\title{
Ciudadanía y democracia cultural. Los desafíos de la culturalidad política en Chiapas
}

\section{Citizenship and Cultural Democracy: The Challenges of Political Culturality in Chiapas}

\author{
Jesús Solís Cruz \\ CESMECA-UNICACH/Observatorio de las Democracias: sur de México y Centroamérica

Resumen:

Una serie de sucesos políticos, registrados en municipios indígenas en Chiapas, ha reabierto el debate en torno a los derechos culturales y su reconocimiento en la entidad. Ocurridos en un ambiente de júbilo de la clase política gobernante por el afianzamiento de la democracia electoral en el estado, estos sucesos aparecen como excepciones de un marco de realidad política modelo. En este artículo retomo tres sucesos políticos, en igual número de municipios, con el propósito de trazar, apoyado en la idea de acontecimiento, una reflexión y un análisis sobre las posiciones y condiciones políticas desde las que diversos agentes políticos están planteando reclamaciones de derechos culturales. Situando cada suceso a la par de los desarrollos teóricos en torno a este tipo de reclamaciones, reviso las posibilidades e inconsistencias de una propuesta de derechos diferenciados para una realidad como la chiapaneca.

Palabras clave: derechos culturales, multiculturalismo, pluralismo, política local, acontecimiento.

\section{Abstract:}

A series of political events reported in indigenous municipalities in Chiapas State has reopened a debate about cultural rights and their recognition in Chiapas State. Occurring within an atmosphere in which the ruling political class was rejoicing about the consolidation of electoral democracy in Chiapas State, these events seem exceptions within the framework of a model political reality. Using the notion of event, this article takes up three political events that took place in three different municipalities with the objective of delineating reflection and analysis of the political positions and conditions from which various different agents are claiming cultural rights. Setting each event parallel to the theoretical developments regarding this type of claim, it reviews the possibilities and inconsistencies of a differentiated rights proposal within the reality of Chiapas State.

Keywords: cultural rights, multiculturalism, pluralism, local politics, event. 


\section{Introducción}

E I El filósofo esloveno Slavoj Zizek, en uno de sus más recientes libros, reflexiona en torno al acontecimiento, el cual presenta una dimensión de enigma y una gran relevancia en el curso de la vida social. En su definición mínima de acontecimiento Zizek hace referencia a la condición traumática, perturbadora y de apariencia repentina de un hecho o acto que fisura «el curso normal de las cosas; algo que surge aparentemente de la nada, sin causas discernibles, una apariencia que no tiene como base nada sólido» (2014:16). Tal condición acontecimental se puede reconocer en un acto cotidiano prosaico, en un suceso histórico fundacional (cristianismo, budismo, stalinismo, etcétera), como en un acto político. Es consustancial al acontecimiento el hecho de que de forma insospechada cambie el orden de las cosas.

En este artículo, apoyándome en esta idea de acontecimiento, analizo y reflexiono sobre los derroteros de las reclamaciones de los derechos culturales, en un sentido amplio, y sus vinculaciones con la ciudadanía y la democracia. Registro, reconociendo su condición inacabada e inabarcable, conceptos y valores ético-políticos que devienen inherentes a la discusión sobre derechos culturales tales como: tolerancia, reconocimiento, cultura, conflicto, multiculturalidad, pluralidad, indigenismo. Para llevar adelante el estudio me remito, como referente empírico, a una serie de sucesos políticos recientemente ocurridos en Chiapas.

Me propongo, así, enfocar acontecimientos políticos recientes de un modo acontecimiental (Zizek 2014) ${ }^{1}$ para resituar y actualizar la discusión sobre derechos culturales, procurando mostrar su contenido, sus posibilidades e inconsistencias en una realidad como la chiapaneca. Es decir, la serie de acontecimientos que aquí se describirán servirán como vehículos detonantes de una discusión que pretende afrontar la posibilidad o los retos de construir ciudadanía y democracia desde una reclamación de reconocimiento de diferencia cultural.

1 El modo acontecimental se entendería como observar y «pasar de una noción de acontecimiento a otra destacando los callejones sin salida que los impregnan» (Zizek 2014:19), es decir, situando justo sus condiciones de imprevisibilidad e inaprensibilidad aparente. 


\section{¿Sociedad civil indígena versus sociedad política? \\ - El acontecimiento original y las claves para comenzar}

El 25 de mayo de 2016, un grupo de hombres irrumpió en una reunión privada en la curia diocesana de San Cristóbal de Las Casas, en la que se discutían posibles salidas al conflicto poselectoral registrado en el municipio de Chenalhó, Chiapas. Con la mediación de agentes pertenecientes a la diócesis de San Cristóbal se había logrado reunir, para dialogar en torno al problema de aquel municipio, a comisionados de los inconformes con los resultados del proceso comicial de julio de 2015 para la renovación de ayuntamientos, al presidente de la Cámara de Diputados local y al representante del Partido Verde Ecologista de México (PVEM) en Chiapas.

Enardecido, el grupo de hombres sacó de aquel lugar al presidente de la Cámara de Diputados y al representante partidista, y a enviones los subieron a una camioneta para trasladarlos hasta la plaza principal, en la cabecera municipal de Chenalhó. En aquel lugar los pobladores, inconformes, recrearon un parlamento popular, y en ese marco realizaron una asamblea y un juicio popular. Todo este acontecimiento estuvo lleno de acciones directas y simbólicas que remitín a ritos autoritarios y de autoridad como a rituales de inversión de autoridad política, genérica y racial (El Universal 25/05/2016). ${ }^{2}$ Como resultado de lo anterior, los pobladores inconformes lograron que, por la autoridad del presidente del Congreso local, la alcaldesa electa solicitara licencia al cargo, y se nombrara presidente de aquel municipio a la persona con la que simpatizaban los primeros.

De vuelta a su «normalidad», el presidente del Congreso, en conferencia de prensa narró su versión de los sucesos. Del relato destaca, hacia el final, la singularización que hizo de la situación: el acontecimiento ocurrió en una sociedad indígena; en tal sentido, las formas en que los pobladores se condujeron deben ser comprendidas en el marco de sus particulares formas de vida; incluso señaló que lo sucedido debería llevarnos a reconsiderar la validez y vigencia de sus formas de gobierno por usos y costumbres (Expreso Chiapas 27/05/2016). Fatídicamente, mientras señalaba esto, en el municipio en cuestión sucedían hechos de violencia y sangre por el mismo asunto.

En la declaración del presidente del Congreso de Chiapas, inadvertidamente resonaba uno de los problemas que ha ocupado a científicos, filósofos, sociólo-

\footnotetext{
${ }^{2}$ Las crónicas de los diarios dieron cuenta de estos sucesos y de cómo se expresaron los inconformes, formas que aquí, por consideraciones antropológicas, quiero catalogar como ritualizadas.
} 
gos y antropólogos políticos con mayor afán en el último cuarto de siglo: ¿Puede el reconocimiento de derechos a grupos particulares promover la completa participación de estos en el conjunto de la sociedad?

Revisemos la trayectoria de este dilema, las formas (teóricas) y fórmulas (prácticas) que se han seguido para afrontarla.

Hasta la década de 1970 fue posible observar que los procesos de construcción de ciudadanía en el mundo, aunque eran invariablemente impulsadas por grupos sociales particulares (negros, mujeres, colonos, indígenas campesinos, obreros, etcétera), estos se caracterizaban por buscar la ampliación de derechos sociales, civiles o políticos, según fuesen también las circunstancias del Estado ante el cual se hacía la interpelación. En tal sentido, buscaban la garantía de un tratamiento incluyente e igualitario. Eran luchas por la extensión de derechos ciudadanos en el sentido más enteramente liberal. ${ }^{3}$

En la siguiente década (1980), principalmente en su segunda mitad, cuando comienza la transformación de las coordenadas geoeconómicas y políticas a escala global, se comienza a notar también el giro en las reclamaciones de derechos. Caído el comunismo real, coreado el triunfo del capitalismo liberal, sobreviene el desdibujamiento del campo conflictivo asentado sobre la premisa de la lucha de clases, y casi inmediatamente el desmantelamiento también del Estado bienetarista; el significante que vino a llenar el vacío fue el de las diferencias culturales. Es decir, las acciones públicas contenciosas o los procesos de construcción de ciudadanía a partir de esta transformación geopolítica, comienzan a ser leídos legítimamente solo si son establecidos en los marcos de significación que establece el capitalismo cultural.

En la sociedad angloamericana, por ejemplo, las primeras acciones de reclamación de derechos diferenciados provinieron de grupos minoritarios que cuestionaron la falsa representación e incluso la invisibilización que se hacía de ellos en la estructura curricular de los programas educativos predominantes. Demandaron la separación y la igualación de la representación «de sí» dentro de los programas escolares y en eventos culturales extra-académicos (Turner 1993). Para conseguir su propósito este movimiento, que puede ser caracterizado como autoafirmativo, se apoyó en el concepto de cultura que indistintamente podía entenderse como identidad étnica, estilo de vida o incluso, y de manera casi inadvertida, igualarlo con el desusado concepto de raza.

3 El lector interesado en profundizar en el análisis de procesos de formación de ciudadanías puede remitirse a textos de T. H. Marshall y T. Bottomore (2005), E. Pani (2003), H. Sabato (2003), W. Kymlicka (2003), J. Habermas (1999), T. K. Oommen (1997), B. van Steenberger (1994). 
Esta manera de representar y plantear las demandas de los grupos particulares, con estas insolvencias teórico-conceptuales pero con repercusiones reales en la vida social, ha sido nombrado multiculturalismo.

Aun cuando todavía hoy el significado del término multiculturalismo resulta ambiguo (Schnapper 2004), destaca que, ya fuera como objeto de reflexión, reivindicación o militancia, desde este tipo de acciones afirmativas se problematizara el espacio público. Hicieron visible y objeto de contestación política la supuesta coincidencia entre colectividades, pueblos o etnias y nación. En consecuencia, al reclamar el reconocimiento público de derechos particulares, los grupos demandantes en automático trasladaron la discusión al principio de distinción, eminentemente moderno y liberal, entre lo público y lo privado (cfr. Schnapper 2004). Cuestionaron el supuesto de la neutralidad y la asepsia sociopolítica subyacente en la dicotomía público-privado.

En el anterior sentido, las acciones emprendidas aspiraron no solo a que el Estado (nación) les garantizara el mantenimiento o incluso la conservación de sus fidelidades, raíces o preferencias (culturales, religiosas o históricas) que como sujetos individuales en el ámbito de lo privado les cabe en derecho, sino que estas particularidades, al ser relevantes para la vida de estos grupos, debían estar reconocidas y ser parte constituyente de la misma sociedad política. ${ }^{4}$

Este giro en la identidad y las luchas políticas, además de haber trastocado los supuestos de la homogeneidad cultural nacionales y el postulado dicotómico público-privado, impactó en las políticas nacionales de integración social, particularmente en la de tipo asimilacionista.

A este respecto, cabe mencionar que en América fue en la década de 1940 cuando se discutió, con mayor profundidad y vivacidad en el seno de los gobiernos nacionales, el diseño de políticas orientadas a las poblaciones indígenas. Aunque los términos y conceptos de estas discusiones tenían ciertas variaciones según los contextos y las regiones, el supuesto de partida era la identificación del indio o la condición de sociedad indígena como problema, en tanto que se ligaba a retraso material e incluso retroceso cultural. Las vías de solución se enunciaban, y buscaban traducir en la política nacional, también de modos distintos: occidentalización, modernización, aniquilación, conservación o combinación de

\footnotetext{
4 Will Kymlicka es el filósofo político que, posicionado desde el multiculturalismo, ha reflexionado en este sentido, situando, más que la diferencia cultural como factor relevante para el reconocimiento de derechos, las condiciones de posibilidad a partir de consideraciones políticas y de justicia. Vale decir también que su propuesta, en su propia valoración, busca trascender la dicotomía multiculturalismo/pluralismo político. Véase Will Kymlicka (1996, 2003).
} 
hábitos autóctonos con los del progreso económico y cultural. Fuese en uno u otro sentido, el fin último era conseguir la integración o asimilación de estas sociedades al resto nacional.

Las experiencias en los países con presencia indígena importante en América Latina fueron diversas, registrándose desde formaciones de reservas indígenas con reconocimientos de derechos territoriales particulares, como el caso de los kuna en Panamá, hasta las que con ambigüedad enaltecían el pasado indígena al tiempo que desaprobaban a las colectividades vivientes para volverlas objeto de intervención mediante políticas públicas. En esta última orientación se encontraron la mayoría de países latinoamericanos.

Que esto fuese así tampoco era fortuito. Los gobiernos nacionales, a través de sus departamentos, institutos, secretarías o ministerios particulares, concertaban políticas y lineamientos dirigidos a la atención de los pueblos indígenas. En la región fue el Instituto Indigenista Interamericano, organismo especializado de la Organización de Estados Americanos (OEA), creado en 1940 e integrado por 17 países, el encargado de encauzar y apoyar la acción en política indigenista de los gobiernos miembros.

El Convenio 107 adoptado por la Organización Internacional del Trabajo (OIT) en 1957, fue otro instrumento positivo de carácter internacional que otorgó protección y estableció normas para regular diversos campos de la vida de los pueblos indígenas y tribales. Destaca del conjunto de ámbitos protegidos el de la tierra, la educación y la salud. Acorde a su época, este Convenio sostenía también un sentido asimilacionista en sus normativas y postulados (véase Hernández 2011).

Este modelo habría de ser duramente cuestionado hacia finales de la década de 1970 por los mismos actores destinatarios de las políticas indigenistas, lo que derivó en la formación de otro que además de buscar la participación se orientó hacia el desarrollo y consolidación de los grupos étnicos. ${ }^{5}$ En el contexto de este indigenismo participativo se registraron las primeras acciones autoafirmativas en la región. En el caso de México destaca la propuesta de cambios a la estructura curricular para reconocer el valor de la enseñanza en lengua indígena en los niveles básicos de instrucción escolar, impulsada por la Asociación Nacional de

\footnotetext{
${ }^{5}$ Cabe hacer mención del papel crítico que también desempeñaron actores como los reunidos en Barbados (de donde resultó la conocida Declaración de Barbados-1971), que impactó fuertemente en la política oficial indigenista latinoamericana. Para una explicación pormenorizada de los derroteros de la política indigenista en México, donde se refiere a lo anterior, consúltese Medina (2007).
} 
Profesionistas Bilingües, A. C. (ANPIBAC). Y a nivel de acciones políticas tempranas las registradas en entidades como Michoacán. Aquí sobresale, del conjunto de expresiones iniciales, la recuperación de memoria y sentidos culturales colectivos, escenificados en el rito de Año Nuevo Purhépecha (Zárate 2001).

Estas acciones autoafirmativas en el contexto político ideológico en que comenzaron a emerger resultaban discordantes principalmente con la ideología de izquierda, centrada aún en la idea de la lucha de clases como motor de cambio social.

Es interesante, en esta línea, observar cómo también de una forma temprana (década de 1970) académicos, que al paso del tiempo se convirtieron en partidarios de movimientos reclamantes de derechos etnoculturales, cuestionaran la relevancia política de estas primeras expresiones reivindicativas culturales: «el hecho de que se observen particularidades étnicas en estos grupos, no autoriza para considerarlos en las actuales circunstancias como portadores de una originalidad que les permita acceder a una 'vía' propia, a realizar sus propios 'esquemas' de desarrollo» (Héctor Díaz-Polanco 1978:21 citado en Bartolomé 1995).

La clave para discutir y analizar, en el anterior planteamiento como en la declaración del presidente de la Cámara de Diputados local ya referida, es relativismo cultural. Y ese no es un problema menor porque a esta clave están ligados valores ético-políticos como el de la tolerancia y el respeto (por el Otro, por la diferencia).

\section{Exclusión/inclusión, particularismo, tolerancia, conflicto social. Segundo acontecimiento}

Casi inmediatamente, sabidos los resultados del proceso comicial de julio de 2015 para renovar ayuntamiento en el municipio de Oxchuc, grupos inconformes iniciaron manifestaciones públicas para denunciar fraude en la elección de la alcaldesa de aquel lugar. En la escalada del descontento se registró desde la impugnación de los resultados electorales por los medios legales (Expediente TEECH/JNE-M/10/2015, TEECH/JNE-M/054/2015, TEECH/AG/05/2015) hasta manifestaciones públicas que derivaron en actos vandálicos y hechos de sangre (La Jornada 02/06/2016, Cuarto Poder 08/03/2016).

En el entretanto los actores políticos involucrados denunciaban de un lado no solo fraude electoral, sino control patrimonial del poder local: la alcaldesa electa 
por segunda ocasión (la primera para el periodo 2005-2007) era esposa del edil saliente, quien a su vez había ocupado otros cargos de elección popular. Por otro lado hubo quienes manifestaron que el móvil del descontento era la diferencia de género: la incapacidad que existe en estos espacios, causada por comportamientos machistas, para aceptar la igualdad de género. La representación de la Cámara de Diputados locales, por su lado, se pronunció por usar los cauces positivos reglamentarios (solicitud de licencia indefinida por parte de la alcaldesa electa) en primera instancia, para luego acudir a los usos y costumbres del pueblo indígena como medio de pacificación y conciliación (véase las crónicas en La Jornada 02/06/2016, Cuarto Poder 08/03/2016).

Los árbitros legales intervinientes zanjaron el asunto del modo siguiente: el Tribunal Electoral del estado de Chiapas dictaminó improcedente la solicitud de juicio de nulidad electoral de los querellantes. Lo que avivó las acciones de protesta. La alcaldesa, una vez que solicitó licencia, se inconformó y demandó ante el Tribunal Electoral de Poder Judicial de la Federación (TEPJF) la restitución de sus derechos políticos. Este tribunal resolvió procedente su solicitud y ordenó a las autoridades competentes en el estado garantizar el cumplimiento de esta sentencia. En vista de que no existen las condiciones de paz y seguridad en el municipio de Oxchuc, el Congreso del estado, órgano encargado de dar cumplimiento a la sentencia del Tribunal, en los hechos, no ha restituido los derechos políticos a la alcaldesa electa. En el municipio funciona como gobierno uno que los grupos inconformes establecieron. Es decir, el problema ha estado y sigue entrampado en los mismos dilemas: fraude electoral, control caciquil del poder, violencia de género, violación de derechos políticos, usos y costumbres comunitarios.

¿Es este caso otro ejemplo representativo de la tensión entre el derecho positivo y el consuetudinario? ¿Es la insensibilidad y la intolerancia ante las diferencias lo que subyace en situaciones como estas? ¿Son las visiones de mundo las que aquí se encuentran enfrentadas? ¿Cómo dar respuesta desde consideraciones de orden cultural que son en la misma medida de tipo político?

Antes he dicho que el multiculturalismo, como propuesta ideológica, de reivindicación o militancia, tiene el mérito en sus comienzos de haber problematizado la relación entre cultura y sociedad política (Turner 1993). Decantó en acciones autoafirmativas sustentadas en nociones, en general poco precisas, de identidad social y cultural. Para algunos académicos este tipo de multiculturalismo resultó en una posición hueca que trata a todas las culturas locales del modo en que el 
colonizador acostumbra tratar a sus colonizados: como «autóctonos» cuyas costumbres hay que conocer y «respetar» (Zizek 2010).

Esto es, el multiculturalismo es una forma inconfesada, invertida, autoreferencial de racismo, un 'racismo que mantiene las distancias': 'respeta' la identidad del Otro, lo concibe como una comunidad 'autentica' y cerrada en sí misma respecto de la cual él, el multiculturalista, mantiene una distancia asentada sobre el privilegio de su posición universal. (...) El respeto multicultural por la especificidad del Otro no es sino la afirmación de la propia superioridad (Zizek 2010:64-65).

Ernesto Laclau, en la misma línea de reflexión anterior, llamó la atención sobre el riesgo de entrampamiento que conlleva la afirmación llana de los valores culturales en oposición a las instituciones occidentales (entiéndase europeas y angloamericanas). Lo que resulta de tal postura, indicó, es una oposición entre dos particularismos; un dilema que no es más que el callejón que conduce directamente hacia el autoapartheid (Laclau 1996:63).

En términos políticos Giovanni Sartori (2001) ha señalado que el multiculturalismo, en el sentido que se ha venido señalando, es una postura que segrega socialmente, que no propicia el acercamiento y la convivencia cívica entre grupos culturalmente diferentes, como sí lo hace, alentando reglas y valores firmes, el pluralismo, paradigma que él defiende.

De las críticas que se han hecho al multiculturalismo destaca el señalamiento de que promueve una expresión despolitizada de las relaciones en la sociedad. Es en tal sentido el resultado de una concepción de mundo posideológico, donde ya no tiene lugar dicotomías como izquierda-derecha, sino que el valor que define las relaciones es la diferencia sociocultural. Constituye, en esa línea, una ideología del capitalismo global neoliberal (Zizek 2010).

Adam Kuper ha sido otro de los académicos críticos con el multiculturalismo. Ha llamado la atención sobre el entendimiento autocentrado y el valor absoluto que se le ha otorgado al concepto de cultura; como conocedor de la experiencia segregacionista sudafricana, alerta sobre las implicaciones morales y políticas de centrarse en la cultura como factor explicativo y fundacional de las relaciones, en tanto que distrae de «lo que tenemos en común, en vez de animarnos a establecer comunicaciones que trasciendan las fronteras nacionales, étnicas y religiosas, para aventurarnos seguidamente a través de ellas» (2003:283). Este mismo autor detalló la correlación encontrada, en el impulso a ideas e iniciativas (políticas e incluso empresariales) de tipo culturalista, entre organismos no gubernamenta- 
les de presencia internacional, la Organización de las Naciones Unidas (ONU) y el Banco Mundial, y movimientos de tipo nativista. Sin negar el valor positivo que pudieran tener las iniciativas culturalistas y el reconocimiento de derechos diferenciados, interrogó sobre los fines y las consecuencias políticas que pueden tener en las poblaciones.

En esa línea la pregunta, de gran vigencia como lo muestran los sucesos referidos al comienzo de este parágrafo, es si la conquista de nuevos derechos (diferenciados) es suficiente para la distensión social, la anulación de desigualdades y diferencias. Existen posturas que señalan que no, incluso hacen referencia a situaciones en las que se ha observado exacerbación de conflictos étnicos y hasta el favorecimiento de prácticas de exclusión de individuos o comunidades sobre bases racistas (Kuper 2003). ${ }^{6}$

Se encuentran, por otro lado, posiciones teóricas que postulan la viabilidad y la obligación moral, incluso, de tales reconocimientos como medidas resarcitorias por agravios históricos (véase Taylor 2001). Sin embargo, se llega a afirmar también que las reivindicaciones y los reconocimientos se vuelven ineficaces si no están acompañados por luchas que intenten el equilibrio en la distribución económica y social. Es decir, las políticas de reconocimiento deben combinarse o correlacionarse con políticas redistributivas (Fraser 1998 citado en Grimson 2011).

El sentido de este planteamiento ha llevado a postular la necesidad de crear una democracia cultural. Es decir, un régimen que, recuperando los fundamentos de la vida democrática, apunte hacia el equilibrio y la construcción de parámetros equitativos e incluyentes en la sociedad, al tiempo que sería sensible a las diferencias culturales. Esto ha conducido a interrogarse si es posible extender el welfare state a la cultura. Es decir, ¿debería ser ampliado el Estado bienetarista que pretendió cerrar la brecha entre la igualdad formal y la realidad de las desigualdades económicas y sociales para responder a la nueva crítica que proclama el reconocimiento de derechos culturales? (Schnapper 2004:136).

Aun cuando existen posturas académicas que se inclinan por la creación de un Estado de bienestar culturalista, como las que apunté antes, es también cierto que, a diferencia del orden económico, al que en su sentido original el Estado

6 De hecho, de una forma bastante temprana en el artículo que se ha venido citando, Adam Kuper llamó la atención sobre el riesgo que implicaba definir la ciudadanía en algunos países europeos a partir de consideraciones culturales (a la vez sustentada en nociones de raza y sangre), porque no solo estaba dando lugar a nuevas inclusiones con signo progresista sino a prácticas xenofóbicas alentadas y capitalizadas por grupos derechistas. Hoy es aún más patente cómo partidos políticos de derecha con gran éxito electoral, en países europeos y en los Estados Unidos, están realizado una política del miedo sustentada sobre discursos xenófobos. 
apuntaba para intervenir, que puede considerarse de mayor concreción y constituido por las prácticas sociales, lo cultural es mayormente difícil de aprehender y definir (Schnapper 2004).

La dificultad reside, como hemos venido reflexionando, en la «traducción» de estas reclamaciones a las prácticas sociales y políticas. O lo que es lo mismo: el reto está en pensar cómo traducir estos reclamos en instituciones que garanticen la convivencia de los sujetos en el marco de valores democráticos. Es necesario, y aquí coincido con Dominique Schnapper (2004) y adelanto una de mis conclusiones: razonar en términos de instituciones. ${ }^{7}$ Sin estas se corre el riesgo de caer en improvisaciones y concesiones, amén de distraer la atención de problemas reales. Aunque pareciera contradictorio, razonar en el anterior sentido nos conduce a una institucionalización del conflicto (Lefort 2004) y a buscar en esa medida la solución por los cauces institucionales y principios democráticos.

Paradójicamente, en el acontecimiento referido en este apartado, los actores sociales, políticos y jurídicos participantes están apelando precisamente a valores democráticos, dándoles, algunos más que otros, énfasis culturales. Las respuestas que las instituciones estatales han dado al conflicto no han resultado viables, hasta hoy, para las partes. Y en esa medida no parece, en lo inmediato, que una consideración de orden cultural sea capaz de dar salida a un conflicto eminentemente político. ${ }^{8}$

\section{¿Usos y costumbres? Más elementos para discutir la culturalidad política o tercer acontecimiento}

El 23 de julio del año en curso, en un encuentro cara a cara con una multitud que reclamaba la atención de los compromisos que durante su campaña electoral estableció el presidente municipal de Chamula, con otros tres miembros del ayuntamiento, fue asesinado y ultimado a tiros en la plaza central de la cabecera mu-

\footnotetext{
7 Instituciones se entiende aquí como estructuras de tipo social que tienen como meta organizar las vinculaciones y los comportamientos entre los individuos sobre la base de reglas y normas positivas (cfr. Elias 2008).

8 Lo mismo puede decirse para el caso en el municipio de Chenalhó. En un interesante artículo de opinión periodística, Rafael Landerreche, conocedor directo de la situación sociocultural de este municipio, reflexiona críticamente sobre la dimensión particular de género con que se ha buscado caracterizar el problema. Él cuestiona y va más allá de este enfoque particularista para situar factores de orden político como predominantes en la conflictividad sociopolítica. Véase Rafael Landerreche (La Jornada 03/10/2016).
} 
nicipal de aquel lugar. Entre los posibles móviles se habló de revanchas políticas personalizadas e irritación ciudadana generalizada por la falta de otorgamiento de recursos económicos comprometidos a sectores de aquel municipio. Tres días después de los sucesos el Congreso dio posesión al nuevo alcalde, mismo que hubo no solo de vigilar el marco legal que corresponde a la asunción del poder político formal, sino los que tienen de «uso y costumbre» en este pueblo.

En su primera declaración pública, el recién nombrado presidente municipal señaló que propiciaría un gobierno incluyente sin distinciones partidistas. Una alusión discursiva a la idea de que la presencia de partidos políticos o el pluripartidismo, en estos espacios locales, son detonantes de conflicto social. Un miramiento particularmente relevante en un caso como el de Chamula en el que, en la historia contemporánea, los actores políticos locales y regionales dominantes han construido y promovido una identidad grupal ligada a rasgos de identificación política (con el Partido Revolucionario Institucional, PRI) y religiosa (catolicismo popular). ${ }^{9}$ De hecho, el alcalde asesinado fue el primero en toda la historia política del municipio que ganó la contienda electoral siendo postulado por un partido distinto al PRI: Partido Verde Ecologista de México (PVEM); él mismo en el pasado había desempeñado el mismo cargo, en representación del PRI.

El 8 de octubre, poco más de dos meses después de haber asumido el cargo, el nuevo presidente presentó su renuncia. Las razones aducidas: insolvencia financiera del municipio, lo que volvía irresoluble no solo los compromisos y las reclamaciones de servicios y apoyos sociales de los pobladores sino el pago de salarios de los empleados del ayuntamiento; abandono del gobierno estatal a pesar de que después del asesinato del alcalde se nombró a un comisionado para apoyar al gobierno municipal y se creó una mesa política (integrada por legisladores y funcionarios de gobierno) para contribuir a la conciliación; amenazas de muerte a su persona (La Jornada 09/10/2016).

Ante esta nueva situación, el Congreso del estado acudió a la figura plebiscitaria, reconocida en la legislación local, para nombrar un nuevo gobierno. Convocados y reunidos frente al palacio municipal, los representantes de las comunidades y los parajes pertenecientes al municipio de Chamula nombraron un consejo municipal.

Del conjunto de voces que se pronunciaron sobre este suceso sobresale el señalamiento de la realización pacífica, y conforme a los usos y costumbres, del

\footnotetext{
9 Sobre esta composición identitaria véase el trabajo de Jan Rus (2002)
} 
acto político. De forma muy perspicaz un periodista hacía notar también la ausencia de mujeres en el mismo acto (La Jornada 10/10/2016).

La pregunta para el caso de Chamula, a la luz de los acontecimientos, es si el establecimiento o la recuperación de un procedimiento para la toma de decisiones colectivas serán suficientes para atender una crisis que no es solo de falta de asertividad en la administración municipal sino de orden estructural. ${ }^{10} \mathrm{O}$ es que solo se validan estos procedimientos no por su confiabilidad moral y ética (que es decir también política) sino porque son, precisamente, políticamente artificiosos.

La profundidad de la crisis en la que se halla el gobierno local en Chamula nos obliga a revisar el lenguaje y los procesos políticos que han llevado al reconocimiento o la negación de principios y derechos colectivos asentados sobre rasgos identitarios culturales. En esa línea, como en los apartados anteriores, la idea es situar, en lo que sigue, más elementos para comprender y evaluar la política basada en la identidad cultural.

Revisemos ahora, así sea de forma sucinta, lo que a este respecto ha ocurrido en México.

En nuestro país, el convenio 169 de la OIT (sucesor del 107 aludido antes) fue ratificado por el gobierno nacional 1991. En 1992 se reformó el artículo $4^{\circ}$. constitucional, definiéndose a partir de entonces el país como pluricultural y marcando con ello un punto de inflexión en materia de derechos de los pueblos indígenas.

Si bien el reconocimiento tiene un sentido jurídico positivo, impactó también en la identidad política de sectores movilizados para lograr ampliación y reconocimientos de derechos, en general. De forma particular, organizaciones y grupos descendientes de pueblos originarios recuperaron sentidos de identidad grupal para posicionarlos en el espacio público como demandas políticas.

Esta reforma y reconocimiento institucional, que debilitó también las connotaciones discriminatorias de identificarse como indio o indígena, alentó sin duda las acciones y movilizaciones públicas de los grupos indígenas en México. Sin embargo, factores como la democratización de la región latinoamericana, la construcción y el fortalecimiento de redes y alianzas a nivel nacional e internacional impulsoras de agendas en torno a problemas indígenas fueron también decisivos para propiciar formas de identificación, discursos y acciones políticas cifradas en la identidad cultural en nuestro país.

10 Está ampliamente documentado y analizado cómo este municipio ha entrado en las últimas décadas en un ciclo de crisis económica y productiva tan grave que ha impactado de forma irreversible en las estructuras comunitarias y políticas (véase Rus y Rus 2008). 
En esa línea, es imposible eludir el aporte de acciones colectivas precedentes a lo que después será reconocido, en la década de 1990, como movimiento indígena en México. La movilización campesina de las décadas de 1960 a 1980, organizaciones sociales de base (principalmente de izquierda, con distintos signos y corrientes políticas), la pastoral católica con opción por los pobres (en México predominantemente indígena) e incluso la experiencia de agentes de la política institucional indígena, fueron fuentes que nutrieron y heredaron formas de acción y repertorios de movilización al movimiento indígena en el país.

En la década de 1990, como he dicho, el movimiento indígena fue un actor destacado en el campo político del país. Para este momento había ocurrido un tránsito cualitativo en los planteamientos reivindicatorios de derechos de las organizaciones y los pueblos indígenas. Las acciones más de tipo afirmativo, como las que referí antes con la ANPIBAC y el Año Nuevo Purhépecha en Michoacán (comprometidas con reconocimiento curricular escolar, recuperación o revitalización de valores comunitarios), cedieron lugar a programas políticos y culturales de mayor impacto. Muchas organizaciones indígenas a lo largo del país fueron construyendo una agenda de problemas en la que fueron priorizados reclamos no solo de atención de derechos sociales (salud, educación, trabajo, vivienda) sino los de tipo político (participación efectiva, representación, democratización, autodeterminación) y cultural (reconocimiento efectivo de la pluriculturalidad: lengua, formas de vida).

El repunte en este movimiento engarzó con toda la algidez política causada por el alzamiento en armas del Ejercito Zapatista de Liberación Nacional (EZLN) en el país. Aunque hoy parece consustancial la reclamación de derechos sobre cultura indígena al proyecto político del EZLN, lo indiscutible es que en su inicio tales consideraciones no existían.

Líderes, organizaciones y asesores aportaron al EZLN toda la experiencia que sobre los temas de autonomía y derechos indígenas habían adquirido, aportándole también «la dimensión política, nacional e internacional de la lucha indígena, inexistente en los documentos iniciales del EZLN» (Pérez 2007:280).

Devino la relación estratégica: el movimiento indígena se situó como un actor e interlocutor relevante en los procesos políticos impulsados por el EZLN. En este marco se desarrollaron los Diálogos de San Andrés, en los que representantes indígenas y del gobierno mexicano abordaron el tema del reconocimiento de derechos indígenas. Producto de estos diálogos se creó una iniciativa de reforma constitucional (formulada por la Comisión de Concordia y Pacificación conoci- 
da como iniciativa COCOPA que tenía la anuencia del EZLN) que con importantes adiciones y modificaciones legislativas, no reconocidas ni legitimadas por el movimiento indígena y el EZLN, originó la nombrada Ley de Derechos y Cultura Indígena en agosto de 2001. ${ }^{11}$ Esta ley, que ha observado diversas y divergentes ratificaciones y aplicaciones en las entidades federativas al igual que ingentes manifestaciones de inconformidad, carece hasta el día de hoy del marco reglamentario. Es, sin embargo, el marco legal vigente para estos asuntos. ${ }^{12}$

El proceso sociopolítico hasta aquí descrito fue caracterizado por Guillermo de la Peña (1995) como ciudadanía étnica. Con ello este autor pretendió describir el autorreconocimiento que ciertos grupos sociales estaban realizando a partir de su condición identitaria cultural en México; identidad revalorizada en sentido eminentemente político. Para otro contexto social y geográfico, esta misma revaloración de la política a partir de la identidad ha sido nombrada ciudadanía cultural (Rosaldo 2000).

Ciudadanía étnica o cultural conlleva muchas de las premisas que he venido discutiendo antes a propósito del multiculturalismo. Quizás la más destacable es que en esta conceptualización, que en algunos puntos intenta ser prescriptiva, hay una tendencia a singularizar a las sociedades indígenas, reduciéndolas a una condición tan peculiar (en historia, cultura y visión de mundo) que las hace casi inconexas con el resto de la sociedad nacional. Visto así, la ciudadanía cultural o étnica resulta tan incómoda para las democracias como el multiculturalismo por la tendencia a aislar más que a acercar a las sociedades en su diversidad. Existe en la fundamentación analítica una valoración histórica y antropológica desacertada sobre las sociedades indígenas que conduce al encerramiento ya aludido, y a un debilitamiento del alcance descriptivo de la propuesta conceptual.

No obstante, considero relevante, en la proposición conceptual y reflexiva anterior, el hecho de situar como valioso el concepto (jurídico y social) de ciudadanía. ¿Por qué? Porque remite a una membresía, a una pertenencia y, en esta línea, a una forma de identificación (individual y colectiva). En su dimensión positiva titula en los individuos derechos y los sitúa en relación con el Estado nacional. Se crea, en esa medida, una relación política y jurídica del sujeto con una comunidad más amplia (sea esta de su entorno inmediato o no).

\footnotetext{
11 Una breve y documentada reflexión sobre este proceso y el devenir del movimiento étnico en México en las últimas dos décadas se puede hallar en Pérez (2007).

12 Se pueden hallar lecturas sintéticas de este proceso de formación y transformación del movimiento indígena en México, de la evolución jurídica de las reclamaciones indígenas así como de sus expresiones en algunas entidades federativas, en el libro compilado por Aragón (2008).
} 
La ciudadanía étnica o cultural debiera, entonces, enfatizar y preservar el valor positivo de la condición ciudadana: sujetos de derecho. Esta, me parece, tendría que ser una condición básica en todo régimen democrático. El tema crucial, en la amplia discusión que se ha desarrollado sobre los sujetos de derechos y la preeminencia moral de las colectividades o de los individuos, reside en cómo hacer garantes del reconocimiento como agentes éticos a los sujetos de derechos. Es decir, cómo, en el marco de regímenes democráticos, se puede asegurar a todas las personas, en cuanto agentes éticos, «las condiciones de igualdad civil, iguales libertades y oportunidades básicas» (Gutmann 2008:49).

El más amplio acuerdo entre los teóricos, sean considerados comunitaristas o liberales individualistas/multiculturalistas o pluralistas culturales, está en la innegociabilidad de las libertades fundamentales _llamados también derechos humanos-, que no pueden estar coartadas por ninguna autoridad (Vázquez 2001).

Las disputas y los sucesos controvertidos recuperados en todo el texto se sitúan en torno a la definición de los sujetos de derecho. Allí reside en gran medida un reto. Otro está en despejar la pregunta, como ya he venido apuntando, de si en contextos como el chiapaneco, tan precarizados socialmente, el reconocimiento de derechos diferenciados y culturales será suficiente para fortalecer la política democrática y desmantelar las desigualdades (sociales y económicas) a las que está compelido un régimen como el democrático.

\section{«Deshacer los acontecimientos». Consideraciones finales}

Hoy parece que en Chiapas la entrada plena de las comunidades o colectividades indígenas al mundo político (y social) debería estar pautada por la identidad cultural.

El becerro de oro en torno al cual los poderes locales (instituidos y no) han renovado sus danzas políticas es la identidad. ${ }^{13}$ En todo el texto he buscado situar e ilustrar, a partir de sucesos, análisis y abordajes teóricos, las formas en que en diversas latitudes y contextos (incluido Chiapas) se están afrontando temas de convivialidad social y política valorando la relevancia de la particularidad cultural y grupal.

\footnotetext{
${ }^{13}$ Es esta una paráfrasis de la crítica que Peter Sloterdijk (2014) hace de la llustración en su libro Crítica de la razón cínica.
} 
Recapitulo ahora, primero, para problematizar en torno al objeto de interés y, segundo, para concluir con algunas consideraciones que desde mi punto de vista deben tenerse presentes, sea para formulación de política pública en la materia o simplemente para ganar amplitud en la comprensión del tema.

Creo necesario, así, volver sobre el pretexto (rodeo) teórico que hizo posible abrir el análisis y la reflexión: el acontecimiento. Como fue planteado al comienzo, el acontecimiento tiene como condición el hecho de fisurar, de forma repentina e inesperada, «el curso normal de las cosas»; se propicia sin causa discernible, aparentemente de la nada. Los acontecimientos que deliberadamente recuperé: ¿se pueden considerar como tales? Diré, de nueva cuenta con Zizek, que: "Sé muy bien que no había Acontecimiento, solo el curso normal de las cosas, pero, quizás, desgraciadamente, aún así... (creo) que había uno» (Zizek 2014:142). El acontecimiento subyacente, por decirlo de algún modo, es que los actores sociales y políticos participantes de los sucesos relatados, al enmarcar discursivamente el problema en torno a derechos culturales, han condicionado la esfera pública en que debía (y debe) darse la discusión y resolución, privando de sustancia lo realmente relevante: el conflicto político y la incapacidad de hacer gobierno en estos espacios locales. Es decir, se ha propiciado una despolitización de las relaciones sociales bajo la argumentación de la diferencia identitaria cultural.

Si remontamos esa argumentación y situamos circunstancias reales y concretas, compartidas además en los tres sucesos recuperados, observaremos que no es fortuito lo conflictivo que resultan las conversiones partidistas (eufemísticamente catalogadas como transiciones) y transfuguismos políticos («tradicionalmente» del PRI al PVEM) en estos espacios locales. No es el pluripartidismo en sí causa de tensión social, sino las circunstancias en que este se desarrolla y los contextos en que se posibilitan. ${ }^{14}$ Imposible obviar las condiciones socioeconómicas tan precarias en los tres municipios referidos. Existe incluso una estrecha relación entre composición étnica y niveles críticos en índices de desarrollo humano, marginación, rezago social y diferentes categorías de pobreza (véase Villafuerte 2006, Peláez 2012). Es decir, hay una «etnización» de la marginalidad, pobreza y rezago en Chiapas, en la que los municipios en cuestión ocupan lugares destacados.

\footnotetext{
${ }^{14}$ En otros textos hemos discutido y analizado los procesos e intereses políticos que en la última década impulsaron las transiciones políticas y el pluripartidismo en Chiapas. Véase García, Solís y Pérez (2014) y Solís (2016).
} 
Tienen también historias dilatadas de conflictividad social y de atropellos a las libertades fundamentales (por agentes internos y externos). ${ }^{15}$

A la luz de todo lo anterior, una pregunta relevante es si es suficiente con la restitución y el reconocimiento de derechos, incluso los diferenciados. Considero que no.

Sin negar el valor y el aporte que las luchas por el reconocimiento de derechos diferenciados tienen en el campo político, creo que en contextos como el chiapaneco el reconocimiento de las diferencias culturales y la positivización de estas enfrentan serios desafíos en tanto que los sujetos, en principio, no se conciben como portadores de derechos. En ese tenor, creo que es necesario, como adelantaba antes, seguir razonando en términos de instituciones que fortalezcan a los sujetos mismos de derecho.

Y si pensamos en reconocimientos particulares, será importante:

Realizar análisis críticos para discernir en torno a la viabilidad de la política basada en la identidad cultural.

Situar preguntas sobre la ética política de los grupos identitarios.

Explorar y analizar los intereses políticos ligados a la identidad grupal.

Observar los contextos de desigualdad en que se desarrollan o plantean estas reclamaciones: desigualdades sociales, económicas y políticas.

Tener claridad respecto de la medida en que la identidad de grupo fortalece libertades fundamentales y valores democráticos.

\section{Fuentes de consulta}

Aragón Andrade, Orlando (coord.), 2008, Los derechos de los pueblos indígenas en México. Un panorama, México, Secretaría de Cultura del Gobierno del Estado de Michoacán/Universidad Michoacana de San Nicolás de Hidalgo/Asociación de Universidades e Instituciones de Educación Superior/Congreso del Estado de Michoacán.

Bartolomé, Miguel Alberto, 1995, «Movimientos etnopolíticos y autonomías indígenas en México», América Indígena, LV(1-2), pp. 361-382.

Cuarto Poder, «El miércoles designan nuevo edil de Oxchuc», 08/03/2016, México.

Elias, Norbert, 2008, Sociología fundamental, Barcelona, Gedisa.

15 El lector interesado en ahondar en el conocimiento de la realidad sociopolítica de los municipios aquí tratados puede incursionar desde J. Rus (2002), J. Rus y D. Rus (2008), Moguel y Parra (1998), Zúñiga y Parra (1998), Sonnleitner (2012). 
El Universal, «Indígenas de Chenalhó retienen a presidente del Congreso estatal», 25/05/2016, México.

García Aguilar, María del Carmen, Jesús Solís Cruz y Flor María Pérez Robledo, 2014, «Chiapas. Elecciones 2012», en Margarita Jiménez Badillo (coord.), Calidad de democracia en elecciones para gobernador en el Sur-Sureste de México, México, Plaza y Valdés/Universidad Autónoma de Guadalajara.

Grimson, Alejandro, 2011, Los límites de la cultura. Crítica de las teorías de la identidad, Argentina, Siglo XXI Editores.

Gutmann, Amy, 2008, La identidad en democracia, España, Katz.

Habermas, Jürgen, 1999, La inclusión del otro. Estudios de teoría política, España, Paidós.

Hernández Pulido, J. R., 2011, «La OIT y los pueblos indígenas y tribales», Boletín Mexicano de Derecho Comparado, 82, pp. 153-167.

Kuper, Adam, 2003, «The Return of the Native», Current Anthropology, 44(3), pp. 389-402.

Kymlicka, Will, 2003, La política vernácula. Nacionalismo, multiculturalismo y ciudadanía, España, Paidós.

—_ 1996, Ciudadanía multicultural, España, Paidós.

Laclau, Ernesto, 1996, «Universalismo, particularismo y la cuestión de la identidad», en Emancipación y diferencia, Buenos Aires, Ariel, pp. 43-68.

La Jornada, "Ante protesta de opositores la edil de Oxchuc solicita licencia al cargo», 02/06/2016, México.

—_, «Nombrarán hoy concejo en Chamula, tras renuncia del edil», 09/10/2016, México.

- «Nombran concejo en San Juan Chamula», 10/10/2016, México.

Landerreche, Rafael, 2016, «¿Género contra justicia?», La Jornada, 03/10/2016, México.

Lefort, Claude, 2004, La incertidumbre democrática. Ensayos sobre lo político, España, Anthropos.

Marshall, T. H. y Tom Bottomore, 2005, Ciudadanía y clase social, Buenos Aires, Losada (Cristal del Tiempo).

Medina H., Andrés, 2007, "Los ciclos del indigenismo en México: la política indigenista del siglo XX», en María Tarrío García, Sonia Comboni Salinas y Roberto Diego Quintana (coords.), Mundialización y diversidad cultural. Territorio, identidad y poder en el medio rural mexicano, México, UAM-Xochimilco, pp. 113-132.

Moguel Viveros, Reyna y Manuel Roberto Parra Vázquez, 1998, "Los ladinos rurales de Huixtán y Oxchuc: un caso de involución social», en María Eugenia Reyes Ramos, Reyna Moguel Viveros y Gemma van der Haar (coords.), Espacios disputados: transformaciones rurales en Chiapas, México, UAM-Xochimilco-ECOSUR, pp. 69-97.

Oommen, T. K., 1997, Citizenship, Nationality and ethnicity. Reconciling Competing Identities, Reino Unido, Polity Press, Blackwell Publishers.

Pani, Erika, 2003, «La calidad de ciudadano. Pasado y presente», Istor, IV(15), pp. 70-101.

Peláez Herreros, Óscar, 2012, «Análisis de los indicadores de desarrollo humano, marginación, rezago social y pobreza en los municipios de Chiapas a partir de una perspectiva demográfica», Economía, Sociedad y Territorio, XII(38), pp.181-213.

Peña, Guillermo de la, 1995, «La ciudadanía étnica y la construcción de los indios en el México contemporáneo», Revista Internacional de Filosofía Política, 6, pp. 116-140. 
Pérez Ruiz, Maya Lorena, 2007, «Disyuntivas del movimiento indígena en México: algunas reflexiones», en María Tarrío García, Sonia Comboni Salinas y Roberto Diego Quintana (coords.), Mundialización y diversidad cultural. Territorio, identidad y poder en el medio rural mexicano, México, UAM-Xochimilco, pp. 277-300.

Rosaldo, Renato, 2000, «La pertenencia no es un lujo: procesos de ciudadanía cultural dentro de una sociedad multicultural», Desacatos, 3, pp. 39-49.

Rus, Jan, 2002, «La Comunidad Revolucionaria Institucional: la subversión del gobierno indígena en los Altos de Chiapas, 1936-1968» en Juan Pedro Viquiera y Mario Humberto Ruz (eds.) Chiapas, los rumbos de otra historia, México, UNAM/CIESAS, pp. 251-277.

Rus, Jan y Diana Rus, 2008, "La migración de trabajadores indígenas de los Altos de Chiapas a Estados Unidos, 2001-2005: el caso de San Juan Chamula», en Daniel Villafuerte Solís y María del Carmen García Aguilar (coords.), Migraciones en el sur de México y Centroamérica, México, UNICACH-Porrúa, pp. 343-382.

Sábato, Hilda (coord.), 2003, Ciudadanía política y formación de las naciones. Perspectivas históricas de América Latina, México, Fondo de Cultura Económica/El Colegio de México.

Sartori, Giovanni, 2001, La sociedad multiétnica. Pluralismo, multiculturalismo y extranjeros, México, Taurus.

Schnapper, Dominique, 2004, La democracia providencial. Ensayo sobre la igualdad contemporánea, Argentina, Homo Sapiens Ediciones.

Sloterdijk, Peter, 2014, Crítica de la razón cínica, 6a . ed., España, Ediciones Siruela.

Solís Cruz, Jesús, 2012, Ser ciudadano. Ser Indio. Luchas políticas y formación del Estado en Nurío y Tiríndaro, Michoacán, México, El Colegio de Michoacán/Universidad de Ciencias y Artes de Chiapas.

Solís Cruz, Jesús, 2013, «La ciudadanía en México. Una revisión crítica de su vertiente cultural», en Jorge Uzeta (ed.), Identidades diversas, ciudadanías particulares, México, El Colegio de Michoacán/Fideicomiso Felipe Teixidor y Montserrat Alfau de Teixidor, pp. 27-47.

—_, 2016, "Chiapas, la democracia que no fue», en María del Carmen García Aguilar, Jesús Solís Cruz y Pablo Uc (coords.), Democracias posibles: Crisis y resignificación. Sur de México y Centroamérica, México, Universidad de Ciencias y Artes de Chiapas, pp. 243-258.

Sonnleitner, Willibald, 2012, Elecciones chiapanecas: del régimen posrevolucionario al desorden democrático, México, El Colegio de México.

Steenbergen, Bart van (ed.), 1994, The Condition of Citizenship, Londres, SAGE.

Taylor, Charles, 2001/1993, «El multiculturalismo y la política de reconocimiento» Ensayo de Charles Taylor. Comentarios de Amy Gutmann, Steven C. Rockefeller, Michael Walter y Susan Wolf, México, Fondo de Cultura Económica.

Tribunal Electoral del Estado de Chiapas, Expediente TEECH/JNE-M/10/2015, TEECH/ JNE-M/054/2015, TEECH/AG/05/2015.

Turner, Terence, 1993, «Anthropology and Multiculturalism. What Is Anthropology That Multiculturalists Should Be Mindful of It?», Cultural Anthropology, 8(4), pp. 411-429. 
Vázquez, Rodolfo, 2001, Liberalismo, estado de derecho y minorías, México, Paidós/ UNAM.

Villafuerte Solís, Daniel, 2006, Chiapas Económico, México, Secretaría de Educación del Gobierno de Chiapas (Lecturas para entender a Chiapas).

Zárate Hernández, José Eduardo, 2001, Los señores de utopía. Etnicidad política en una comunidad P'urhépecha: Santa Fe de La Laguna-Ueamuo, 2ª . ed., México, El Colegio de Michoacán.

Zizek, Slavoj, 2010, En defensa de la intolerancia, España, Diario Público.

- 2014, Acontecimiento, España, Sexto Piso.

Zúñiga López, Rosa Elva y Manuel R. Parra Vázquez, 1998, «Una mirada al pasado, tres visiones del futuro. Las rebeliones en Santa Martha, Chenalhó», en María Eugenia Reyes Ramos, Reyna Moguel Viveros y Gemma van der Haar (coords.), Espacios disputados: transformaciones rurales en Chiapas, México, UAM-Xochimilco-ECOSUR, pp. 277-294. 